\title{
A model for planning a bicycle network with multi-criteria suitability evaluation using GIS
}

\author{
T. P. Hsu \& Y. T. Lin \\ Institute of Civil Engineering, National Taiwan University, Taiwan
}

\begin{abstract}
Bicycles are becoming an important mode of travel in terms of energy consumption and greening the transportation system of the $21^{\text {st }}$ century. Creating a bicycle network in the urban areas is the key point to encourage the use of the bicycle as the daily mode of personal transportation. In this paper, a multicriteria assessment model was developed to assess the suitability of designing bicycle routes by using a geographic information system (GIS). The criteria selected in this study consist of traffic volume, curb lane width, sidewalk width, speed limit, pavement quality, and curb activity disturbance. They are standardized and summed by weights. The weight values are determined using the fuzzy analytical hierarchy process. By comparing the shortest path with a path suitable for bicycles, the need to modify the street layout and make it more suitable for bicycle traffic is then determined in terms of the relationship between them. This model is a useful tool to analyze the suitability level of the existing street network and generate a street reconstruction program for making the existing street network suitable for bicycle use.
\end{abstract}

Keywords: bicycle, multi-criteria, street planning, fuzzy AHP, GIS.

\section{Introduction}

Encouraging the use of bicycles is a major carbon reduction measure in response to global warming. In addition to recreational use, the use of bicycles should be increased in order to improve the present transportation congestion in most large urban areas, and at the same time make a major contribution to carbon reduction. However, the lack of a comprehensive bicycle network makes it difficult to encourage commuters to use a bicycle in urban areas. In order to create a comprehensive bicycle network, a proper feasibility study must be conducted 
based on travel demand, travel origins and destinations, and the safety of the public that uses the road system, prior to the design and construction of a bicycle network. This paper aims to propose a planning process for a bicycle network by developing a bicycle planning model using a geographic information system (GIS).

\section{Level of service and suitability}

Several studies have been carried out that assessed existing road conditions for the use of bicycles. Botma [1] defined the LOS criteria for a separated bicycle lane based on the frequency of bicyclist meeting and/or passing along a path. The Texas Department of Transportation (TxDOT) [2] has proposed to consider the road conditions for developing a bicycle suitability assessment method. Other research evaluated bicycle level of service of the existing road, such as using bicycle stress levels $[3,4]$ or using bicycle safety index rating (BSIR) [5]. In the city of Hollywood, bicycle planners revised the Davis' index and created a Modified Roadway Condition Index (also called the Epperson-Davis modification) [6]. Landis [7] developed a bicycle interaction hazard score (IHS) and validated the IHS model by using the subjective ranking by cyclists. The TxDOT developed a Bicycle Suitability Score to assess the existing road conditions for bicycle use [8].

\section{Methodology}

This paper presents a bicycle network planning and evaluation approach that consists of a multi- criteria suitability evaluation model of the existing road conditions and a shortest-path algorithm for the selection of a bicycle route. In the evaluation model, the Fuzzy Analytical Hierarchy Process (AHP) is adopted to obtain the weight value. For the shortest path algorithm, the Floyd-Warshall shortest path algorithm is adopted into the GIS system. The Fuzzy AHP for the weight value and the Floyd-Warshall shortest path algorithm is described as follows.

\subsection{The Fuzzy AHP method}

The "Fuzzy Analytic Hierarchy Process (AHP)" is a useful tool to determine criteria for solving the imprecise semantics of the AHP process [9]. Laarhoven and Pedrycz [10] improved the traditional AHP method by introducing the fuzzy theory. By involving the fuzzy theory, the ambiguity of the AHP can be reduced. Buckley made the value of the paired comparison fuzzy within the AHP and used trapezoidal fuzzy numbers. Csutora and Buckley [11] presented the Lambda-Max approach to calculate the weight value of the Fuzzy AHP. This algorithm includes the following steps:

1. Set up a pair-wise comparison matrix and a fuzzy positive reciprocal matrix.

2. Use the method of Lambda-Max and $\alpha$-cut to calculate the fuzzy weight corresponding to the fuzzy positive reciprocal matrix. 
3. After finding each index value of the triangular fuzzy weight, the weights of the group are then integrated using the arithmetic average method. Each criteria of the triangular fuzzy weight can be determined after integration, using the defuzzification formula as proposed by Chen and Hwang [12] and the weight value can be calculated.

\subsection{The Floyd-Warshall algorithm}

The Floyd-Warshall algorithm uses an adjacency matrix to calculate the shortest path of all Origin-Destination (OD) pairs and find the minimum cost path. The algorithm was published in its currently recognized form in 1962 [13]. It mainly uses different observed values to find a new recursive and reduces the algorithm's complexity. Given a network $\mathrm{G}=(\mathrm{V}, \mathrm{E})$, where $\mathrm{V}$ is the set of all nodes, and $\mathrm{E}$ is the set of all links. Then an $\mathrm{N} \times \mathrm{N}$ cost matrix $\mathrm{C}$ is built to check the cost of each element of matrix $C$, where $C_{i, j}$ denotes the cost from node $i$ to node $\mathrm{j}$. If $\mathrm{C}_{\mathrm{i}, \mathrm{k}}+\mathrm{C}_{\mathrm{k}, \mathrm{j}}<\mathrm{C}_{\mathrm{i}, \mathrm{j}}$, it indicates that there is a smaller time cost via the path through node $\mathrm{k}$. In that case let $\mathrm{C}_{\mathrm{i}, \mathrm{j}}=\mathrm{C}_{\mathrm{i}, \mathrm{k}}+\mathrm{C}_{\mathrm{k}, \mathrm{j}}$, and record $\mathrm{k}$. Continue to check the other elements within the matrix until each element is checked in the matrix so as to obtain all the minimum paths.

\subsection{Indicators for a suitability evaluation}

There are five steps for establishing a bicycle suitability evaluation model: the initially proposed indicators, select the indicators, set the weight value, identify the classification threshold value, and calculate the comprehensive evaluation value by combining all indicators. The comprehensive evaluation value of suitability of each link in the network is inputted as a cost for searching the shortest path in the GIS system with the Floyd-Warshall algorithm. We conducted a comparative search for the evaluation indicators from all relevant literatures of bicycle LOS and risk analysis of bicycle traffic, using the most popular adopted indicators considered for the existing road condition. We then selected six indictors for establishing the bicycle suitability evaluation model based on the results of a subjective discussion by experts. The indicators include vehicle traffic volume, curb lane width, sidewalk width, speed limit, pavement quality, and curb activity disturbance. The vehicle traffic volume was obtained from field observations at peak hours. The curb lane width and the sidewalk width were measured under real road conditions. The speed limit was the posted speed limit on that road. Pavement quality was calculated as the percentage of the pavement that was damaged. The curb activity disturbance represented the ratio of the total length of the bus stop area, taxi stop area and loading and unloading zones to the total length of street.

\subsection{Weight value}

The weight of each evaluation indicator was identified by means of an expert opinion survey and the Fuzzy Analytic Hierarchy Process, as shown in table 1. 
Table 1: $\quad$ The weights of the bicycle suitability indicators.

\begin{tabular}{|c|c|c|}
\hline $\begin{array}{c}\text { Bicycle suitability } \\
\text { indicator }\end{array}$ & Feature of indicator & weight \\
\hline Vehicle traffic volume & Negative indicators & 0.1766 \\
\hline Outer-lane width & Positive indicators & 0.1718 \\
\hline $\begin{array}{c}\text { Effective width of the } \\
\text { sidewalk }\end{array}$ & Positive indicators & 0.1643 \\
\hline Speed limit & Negative indicators & 0.1156 \\
\hline Pavement quality & Positive indicators & 0.1469 \\
\hline $\begin{array}{c}\text { Disturbance from road } \\
\text { side activity }\end{array}$ & Positive indicators & 0.2377 \\
\hline
\end{tabular}

\subsection{Bicycle level of suitability (BLOS) and comprehensive evaluation value}

This study classified all the indicator values into six levels, ranging from A (indicating the best) to $\mathrm{F}$ (indicating the worst), with a score ranging from 0 to 5 . The threshold of the classification is an average boundary value based on a questionnaire survey of experts on bicycle traffic. The classification results are shown in table 2 .

Table 2: $\quad$ The threshold of the bicycle suitability index.

\begin{tabular}{|c|c|c|c|c|c|c|}
\hline Indicator & $\begin{array}{c}\text { Level A } \\
\text { (0score }\end{array}$ & $\begin{array}{c}\text { Level B } \\
(1 \text { score })\end{array}$ & $\begin{array}{c}\text { Level C } \\
(2 \text { score })\end{array}$ & $\begin{array}{c}\text { Level D } \\
(3 \text { score })\end{array}$ & $\begin{array}{c}\text { Level E } \\
\text { (4score) }\end{array}$ & $\begin{array}{c}\text { Level F } \\
\text { (5score) }\end{array}$ \\
\hline $\begin{array}{c}\text { Vehicle } \\
\text { traffic } \\
\text { volume } \\
\text { (pcu) }\end{array}$ & $>2000$ & $\begin{array}{c}2000 \\
\sim 3000\end{array}$ & $\begin{array}{c}3000 \\
\sim 4500\end{array}$ & $\begin{array}{c}4500 \\
\sim 6500\end{array}$ & $\begin{array}{c}6500 \\
\sim 10000\end{array}$ & $<10000$ \\
\hline $\begin{array}{c}\text { Curb-lane } \\
\text { width (m) }\end{array}$ & $<5.5$ & $4.5 \sim 5.5$ & 3.54 .5 & $2.5 \sim 3.5$ & $1.5 \sim 2.5$ & $>1.5$ \\
\hline $\begin{array}{c}\text { Effective } \\
\text { sidewalk } \\
\text { width (m) }\end{array}$ & $>4.5$ & $3.5 \sim 4.5$ & $2.5 \sim 3.5$ & $1.5 \sim 2.5$ & $1 \sim 1.5$ & $<1$ \\
\hline $\begin{array}{c}\text { Speed limit } \\
\text { (km/hr) }\end{array}$ & $<20$ & $20 \sim 30$ & $30 \sim 40$ & $40 \sim 50$ & $50 \sim 60$ & $>60$ \\
\hline $\begin{array}{c}\text { Pavement } \\
\text { quality (\%) }\end{array}$ & $90 \sim 100$ & $80 \sim 90$ & $70 \sim 80$ & $60 \sim 70$ & $50 \sim 60$ & $<50$ \\
\hline $\begin{array}{c}\text { Disturbance } \\
\text { from } \\
\text { curbside } \\
\text { activity (\%) }\end{array}$ & $95 \sim 100$ & $90 \sim 95$ & $85 \sim 90$ & $75 \sim 85$ & $60 \sim 75$ & $<60$ \\
\hline
\end{tabular}

In order to combine the six indicators into a comprehensive evaluation value, the weight sum value was calculated using the weight value of table 1 . The score of the indicator was set from the best A level of 0 to the worst $\mathrm{F}$ level of 5 . Therefore, the comprehensive level of suitability classification with the weighted 
summed value of the score of indicator was identified using the average score threshold, as shown in table 3.

Table 3: Level of suitability of the comprehensive evaluation value.

\begin{tabular}{|c|c|c|c|c|c|c|}
\hline $\begin{array}{c}\text { Level of } \\
\text { Suitability }\end{array}$ & A & B & C & D & E & F \\
\hline $\begin{array}{c}\text { Weighted } \\
\text { Score }\end{array}$ & $<0.5$ & $0.5 \sim 1.5$ & $1.5 \sim 2.5$ & $2.5 \sim 3.5$ & $3.5 \sim 4.5$ & $>4.5$ \\
\hline
\end{tabular}

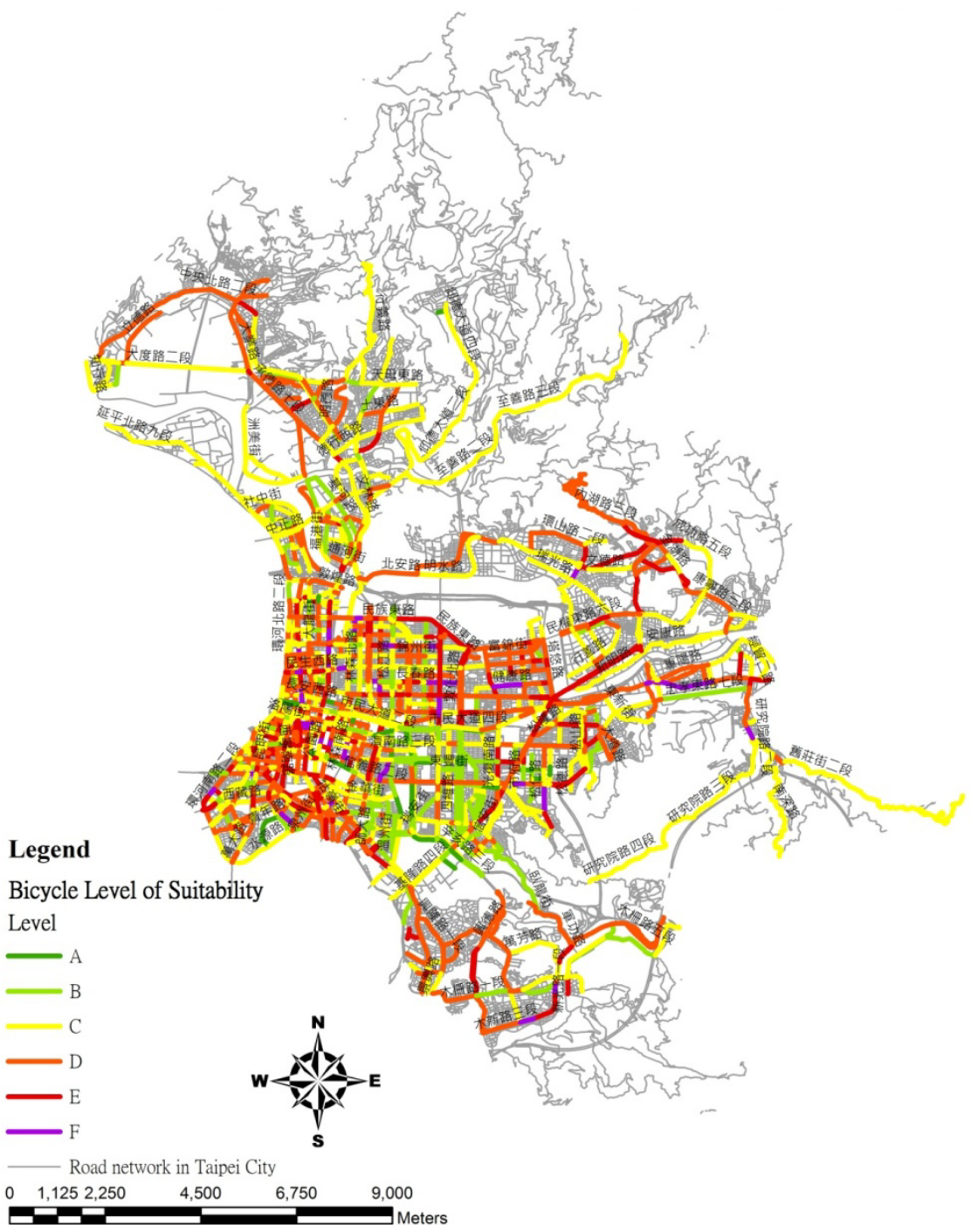

Figure 1: The bicycle suitability level of the roads in Taipei City. 


\subsection{Application of the evaluation model with the GIS}

Taking Taipei City as an example and using the geographic information system (GIS) to build a database, the model is applied to assess the suitability of the road network for bicycles in Taipei. Conducting a field survey of the entire network of Taipei, the data of each indictor are collected and input as map -layer into GIS. After calculating the comprehensive evaluation value, the level of suitability for bicycle in Taipei is illustrated with the level in different colors in fig. 1. Most of the streets are not so suitable for riding bicycle. The streets with A level, colored deep green, locate mostly in the new developed city center.

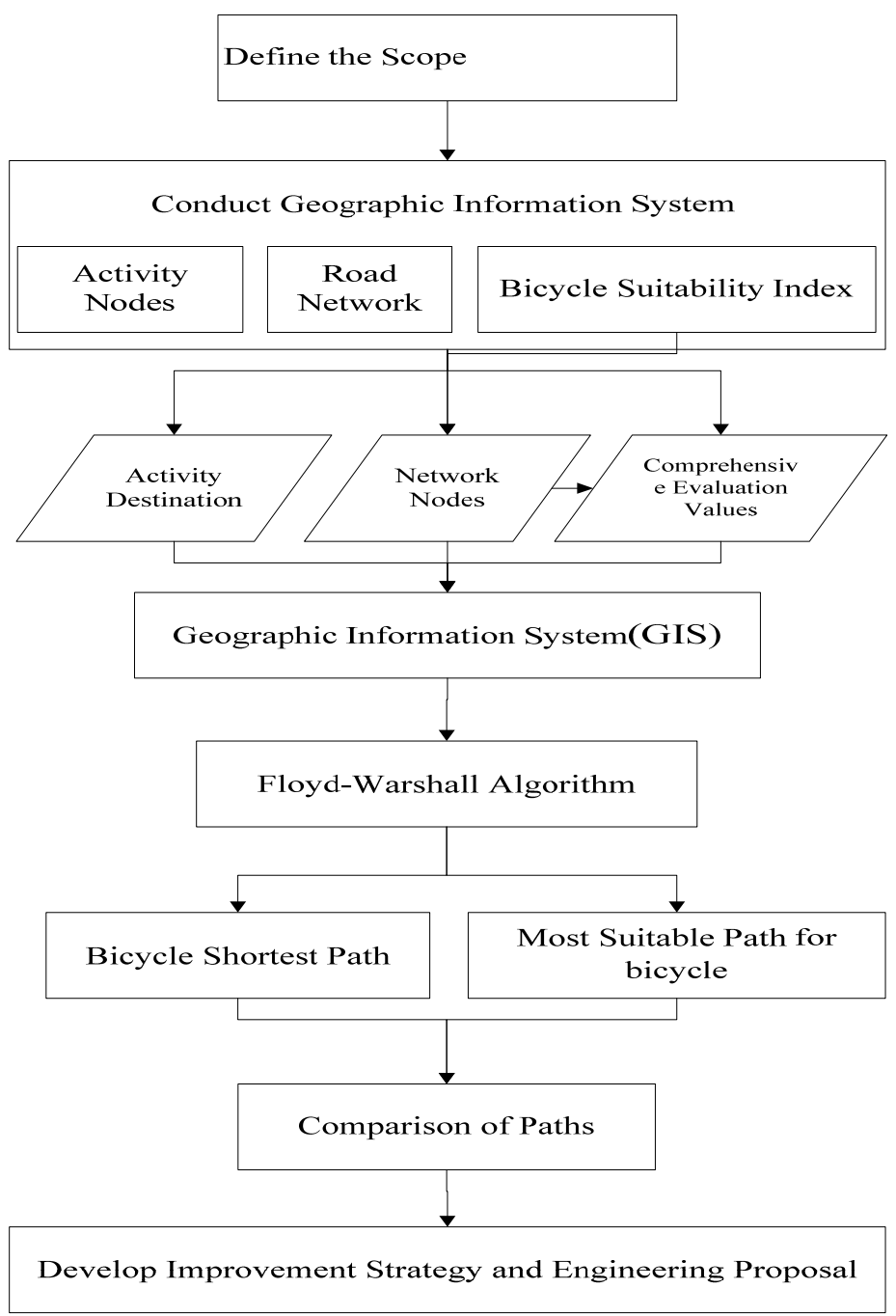

Figure 2: $\quad$ Framework of planning model for bicycle network. 


\section{Planning model for a bicycle path network}

The model for planning a bicycle path was established, using a framework as shown in fig. 2, based on the evaluation of the bicycle suitability mentioned above, and combining with the origin-destination analysis of the bicycle demand. It is the bicycle network planning procedure with the shortest path algorithm.

\subsection{Planning model for bicycle network}

First we determine the scope of the plan. Then the GIS system gets established using the data of the road network. For each link and node of the network a survey is conducted, and the data for each indicator is collected. Using the evaluation model built into the GIS system, the Level of Suitability of each section of road in the network is evaluated and ranked between levels A and F level, and complete with a comprehensive evaluation score. The score is taken as input to establish the most suitable path and the shortest distance path for each origin-destination pair using the Floyd-Warshall algorithm that is built-in in the GIS using $\mathrm{C}++$ program language. The origin-destination pair is identified based on the traffic zones, which are the major trip generators, such as the employment areas or residential areas etc. Then, by comparing the shortest distance and the most suitable path, the shortcomings of the existing network compared to an ideal bicycle path can be identified. If the shortest distance path becomes the most suitable path, then the bicycle network will be the most effective one. If not, some bicyclists will choose to ride on the shortest path, which may be unsuitable for bicycles and risk injury. The difference between the shortest path and most suitable path, allows us to determine the shortcomings of existing network for bicycle. The amount of work required to reconstruct the existing network and turn it into a bicycle-suitable network and make the shortest path become the suitable path can be taken as the basic requirement, and thus the model for planning a bicycle network is established.

\subsection{Applying a suitable bicycle path evaluation}

The comprehensive evaluation values were calculated using the field survey data of each indicator and insert it into the GIS system. We took the district of Ta-An in Taipei to conduct the application case. The network has 194 nodes. The value of the suitability score of every link is shown in fig. 3-a. Based on the score, the Level of Suitability of that particular road section can be classified based on the threshold shown in table 2 for the individual index, and in Table 3 for the comprehensive level. We selected the 36 major activity nodes as trip generators, including schools and MRT stations as the Origin and Destination (OD), as shown in fig. $3 \mathrm{~b}$ with red points.

To determine the most suitable path and the shortest path, we take all nodes as the origin and destination. We then conduct the Floyd-Warshall algorithm to search for the 6984 paths between the 194 network nodes and the 36 major activity nodes. 


\subsection{Path comparison}

When we compare the shortest paths and the most suitable path for bicycles, then we can see that $85.87 \%$ of the OD pairs have a different path then the shortest path and the most suitable path.

Using the statistic t-test, it is evident that the comprehensive evaluation values of suitability for the most suitable paths are significantly different from the value of the shortest paths.

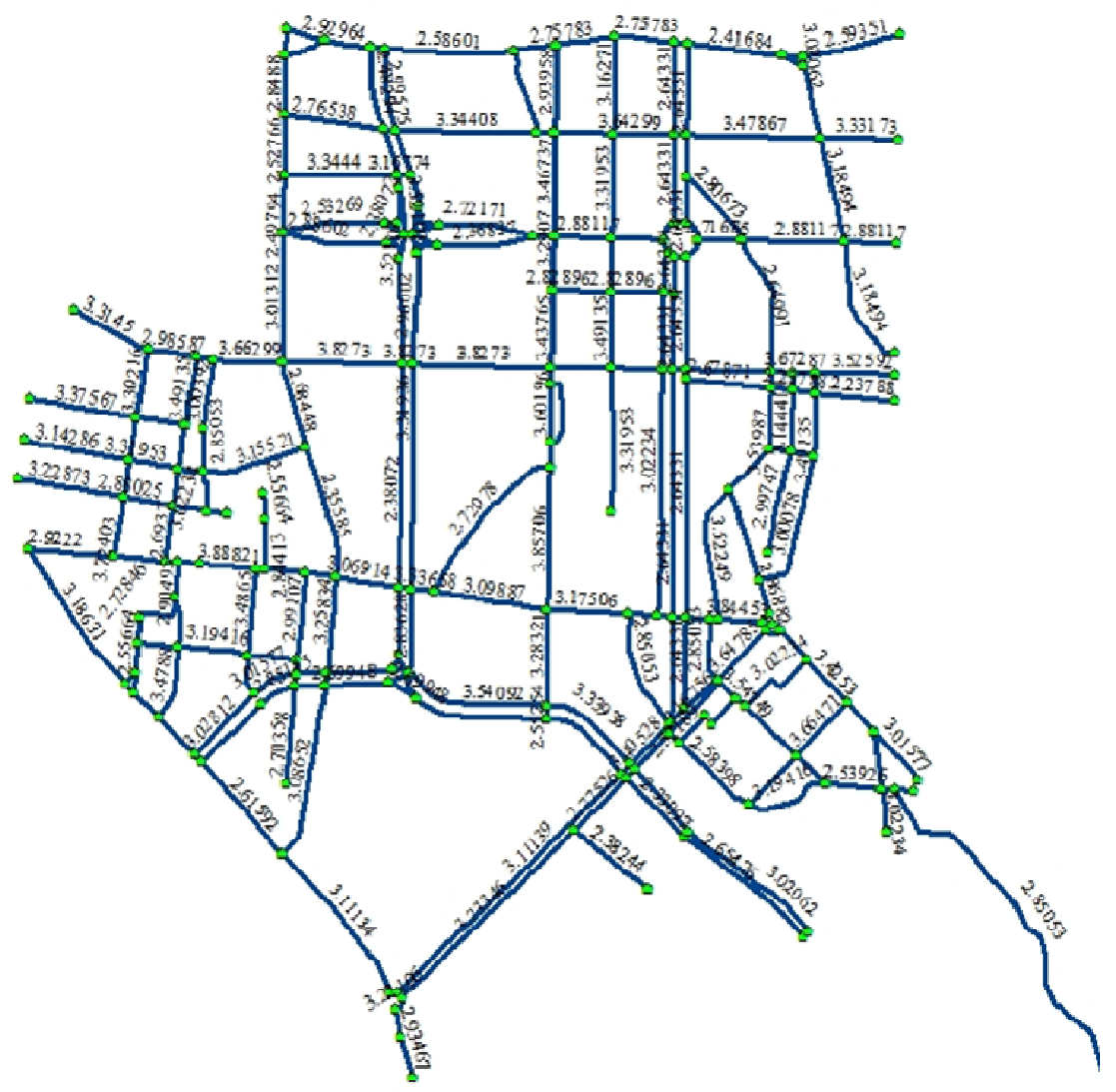

a. The score of suitability for bicycles

Figure 3: $\quad$ Illustration of suitability score for bicycle and major trip generators. 


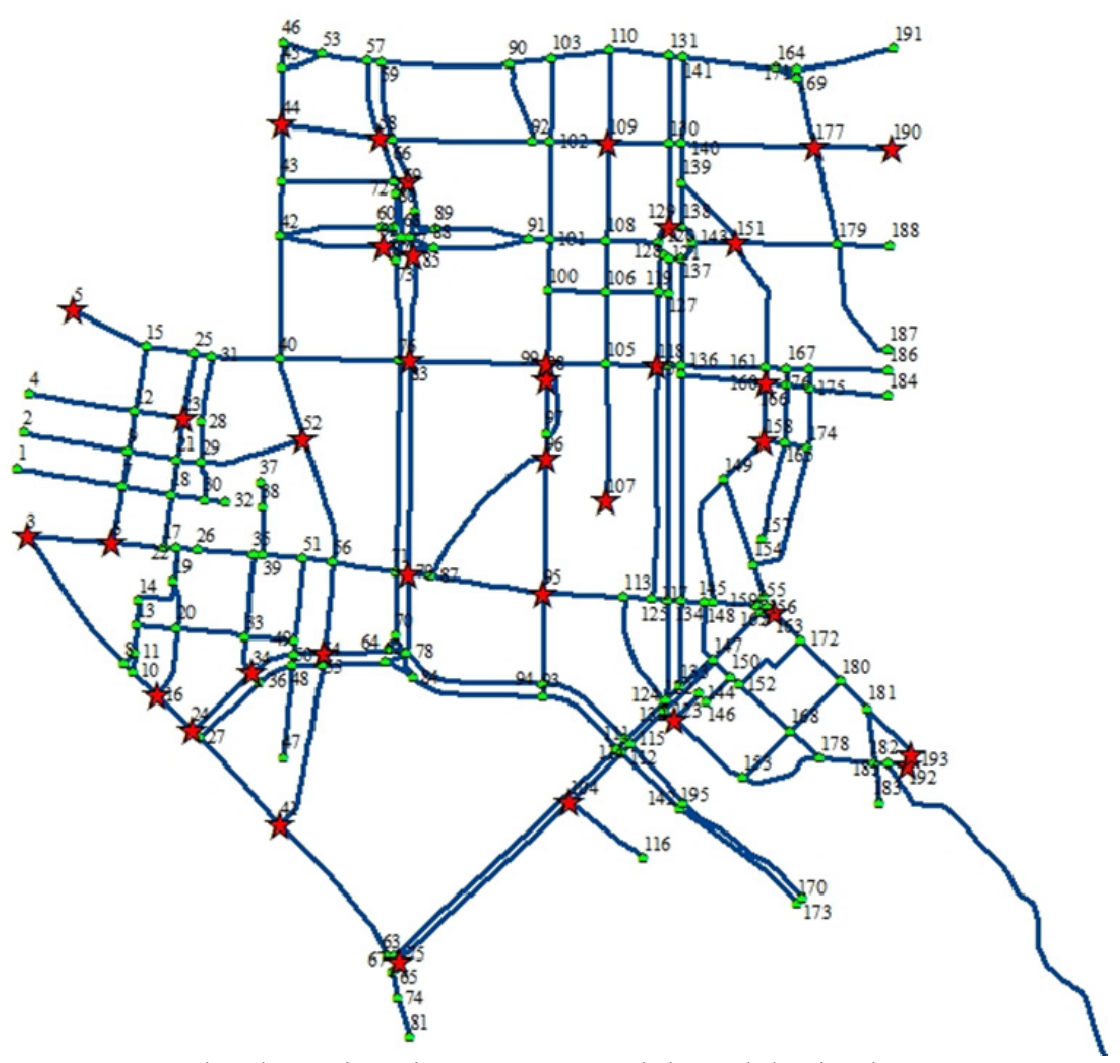

b. The major trip generators: origin and destination

Figure 3: Continued.

\section{Conclusions and suggestions}

Developing a comprehensive model for planning a bicycle network to help with reducing our carbon footprint will be one of our first professional challenges in promoting bicycle usage in the future. A planning model must be able to evaluate the existing road system in terms of bicycle use. It also must conduct a route selection for connecting the origin and destination based on the bicycle travel demand. In this paper, we developed a planning model and applied it to a practical application. The huge difference between the shortest path and a bicycle suitable path indicates that a vast amount of reconstruction work will be required to improve the roads and make them bicycle suitable. This work can be identified using the planning model developed in this paper. In future studies, additional details about the evaluation indexes can be provided, as well as how to generate more suitable reconstruction projects to improve bicycle suitability of the road network by involving more resources. 


\section{References}

[1] Botma Hein, "Method to Determine Level of Service for Bicycle Paths and Pedestrian-Bicycle Paths", In Transportation Research Record 1502. TRB, National Research Council, Washington, DC, pp. 38-44, 1995

[2] Texas Transportation Institute, Bicycle Suitability Criteria for State Roadways in Texas. Research Report 3988-S, Texas Dept. of Transportation, June 1997

[3] Sorton, A., Walsh, Th., "Bicycle Stress Level as a Tool to Evaluate Urban and Suburban Bicycle Compatibility" Transportation Research Record 1438, National Research Council, Washington, DC, pp. 17-24, 1994

[4] Sorton, A., "Measuring the Bicyclist Stress Level of Streets" In Transportation Congress: Civil Engineers - Key to the World Infrastructure. Proceedings of the 1995 Conference, American Society of Civil Engineers, San Diego, CA, pp. 1077-1088, 1995

[5] Eddy, N., "Developing a Level of Service for Bicycle Use", In Pro Bike/Pro Walk 96 Resource Book. Proceedings of the Ninth International Conference on Bicycle and Pedestrian Programs Resource Book, Bicycle Federation of America and Pedestrian Federation of America, pp. 310-314, 1996

[6] Epperson, B., "Evaluating Suitability of Roadways for Bicycle Use: Toward a Cycling Level-of-Service Standard", In Transportation Research Record 1438. TRB, National Research Council, Washington, DC, pp. 9-16, 1994

[7] Landis, B. W., "Real-Time Human Perceptions: Toward a Level of Service", Paper No. 970428. Presented at the Transportation Research Board's 76th Annual Meeting, TRB, National Research Council, Washington, DC, January 1997

[8] Shawn M. Turner, C. Scott Shafer, and William P. Stewart, "Bicycle Suitability Criteria for State Roadways in Texas", Research Report 3988-S, Texas Transportation Institute, Texas Dept. of Transportation, June 1997

[9] De Grann, "Extensions of the Multiple Criteria Analysis Method of T.L. Satty", National Institute for Water Supply, 1980.

[10] Laarhoven, P. J. M., Pedrycz, W., “A Fuzzy Extension of Saaty’s Priority Theory”, Fuzzy Sets and Systems, Vol.11, No.3, pp.229-241, 1983

[11] Csutora, R. and Buckley, J. J., "Fuzzy Hierarchical Analysis: the LambdaMax Method", Fuzzy Sets and Systems, Vol.120, pp.181-195 , 2001

[12] Chen, S. J., \& Hwang, C. L., "Fuzzy Multiple Attribute Decision Making Method and Application: A State-of-the-Art Survey", Spring-Verlag, 1982

[13] Floyd, R. W. “Algorithm 97”. Communications of the ACM 5-6, 345, June 1962 